This is the authors' version of an article published in Renewable Energy, Vol.125, 2018

this version by the publisher prior to publication. https://doi.org/10.1016/j.renene.2018.02.121

\title{
1 Direct Power Control for Grid-Connected Doubly Fed Induction Generator Using Disturbance Observer Based Control
}

${ }_{4} \quad$ Mahdi Debouza ${ }^{\mathrm{a}}$, Ahmed Al-Durra $^{\mathrm{a}, *}$, Rachid Errouissi ${ }^{\mathrm{a}}$, S.M. Muyeen ${ }^{\mathrm{b}}$

${ }^{a}$ Department of Electrical and Computer Engineering, Khalifa University of Science and Technology, Sas Al-Nakhl Campus, P.O. Box 2533, Abu Dhabi, United Arab Emirates ${ }^{b}$ Department of Electrical and Computer Engineering, Curtin University, Perth, Australia

8 Abstract

9 A disturbance observer based control method for a grid-connected doubly fed 10 induction generator is presented in this study. The proposed control method 11 consists of a state-feedback controller and a disturbance observer (DO). The ${ }_{12}$ DO is used to compensate for model uncertainties with the aim of removing 13 the steady-state error. The control objective consists of regulating the stator currents instead of the rotor currents in order to achieve direct control of the stator active and reactive powers. Such a control scheme removes the need for an exact knowledge of the machine parameters to achieve accurate control of the stator active and reactive powers. The main advantage of this control method is ensuring a good transient performance as per the controller design specifications, 19 while guaranteeing zero steady-state error. Moreover, the proposed control method was experimentally validated on a small scale DFIG setup.

21 Keywords: WECS, DFIG, disturbance observer based control (DOBC)

22 $M S C$ : RENE-D-17-02808

\footnotetext{
* Corresponding author

Email address: aaldurra@pi.ac.ae (Ahmed Al-Durra)

$U R L:$ www.pi.ac.ae (Ahmed Al-Durra)
}

Preprint submitted to Journal of Renewable Energy 


\section{Introduction}

The global power consumption over the past years increased significantly due to the industrial and population growth. Natural fossil resources such as oil, coal, natural gas, etc. have many drawbacks, environmental issues for instance. Renewable energies like solar and wind are environmental friendly. Among many renewable energy sources, wind energy is one of the fastest growing source nowadays. According to the wind global energy council, the global total wind energy installation in 2015 was close to $433 \mathrm{GW}$, and the expected cumulative installed capacity by 2020 is 791.9 GW [1]. Doubly-fed induction generator is an electric machine that is fed with $\mathrm{AC}$ currents in both their stator and rotor windings. Nowadays, the majority of doubly-fed induction generators are three-phase wound-rotor induction machines. They have many advantages such as speed operation range between $\pm 30 \%$ of the synchronous speed, complete independent control of power exchange to and from the grid when controlled with power converters, and reduced power losses and cost due to the use of small scale power converters which is about only $30 \%$ of the generator rating [2, 3]. The common techniques of controlling electric machines are the vector control or field oriented control, direct power, and direct torque control 4, 5]. Many control methods such as proportional integral, sliding mode, model predictive, disturbance observer based, intelligent control, and H-infinity were applied to the DFIG system. The conventional proportional integral control is the most basic control method used to control DFIG based wind energy conversion system (WECS). It is easy to design and implement. In addition, this control can use direct power control [6, 7], vector control [8], or even a combination of the two control schemes 4]. Moreover, different DFIG models including $d q$-synchronous reference frame 4 and $\alpha \beta$-reference frame [8] models are used. In [7], the experimental validation of small scale DFIG using proportional integral control is conducted The inability to operate under different operating points and control parameter tuning are the main drawbacks of this control method. Sliding mode control is a robust control method which 
has very high tracking accuracy and robustness to system parameters variations [9, 10] . This method can be used to control the stator active and reactive powers directly without using $d q$-transformation [11. Chattering and high frequency switching are the main drawbacks of sliding mode control and pulse width modulation techniques cannot be used easily to implement sliding mode control.

Model predictive control is becoming very popular recently. It uses the system model to predict system performance in the next time step and uses optimization of objective functions that considers certain constraints to develop the controller 12 14. Model predictive control usually follows the direct power control [15, 16. The disturbance observer based control contains a combination of a controller and an observer. The controller is used to achieve the transient performance and the observer is used to achieve the steady-state error requirements. This control method was implemented when the rotor currents are used to generate the rotor reference voltages [17], and when the stator currents are used to generate the rotor reference voltages [14. This method provides excellent performance under different speed operation modes, yet the observer design needs modifications to be implemented effectively on real DFIG setups. Intelligent control methods usually do not consider the system model to develop the controller. This advantage is very useful when large scale DFIG systems are considered [18]. Intelligent control was implemented on real DFIG setups [19, 20]. Intelligent control methods can be used to tune the PI controller gains DFIG control [21]. The H-infinity control is a robust control method deals with the control as an optimization problem. It can be used for energy capture optimization [22], DFIG power and torque control 23, regulation of reactive power, and rotor angular speed [24]. This type of control requires high mathematical knowledge and calculations which makes it very difficult to be implemented in real time controller.

Three main aspects need to be considered when designing DFIG controller. Firstly, the DFIG model and system parameters such as mutual inductance are normally required to design a robust controller. However, obtaining accurate DFIG model and measuring exact system parameters is a difficult task, for they 
can change over time and environmental conditions. Secondly, wind speeds are not predictable and can suddenly change. Thirdly, when the system operator requests certain active and/or reactive powers from the DFIG, considering power availability, the controller response should be fast enough to fulfill the operator's requirements. Therefore, the challenging part is to effectively control the DFIG system without the need of exact system parameters knowledge and under external disturbances such as wind speed variations, grid voltage dip, etc. In this paper, the proposed controller focuses on the DFIG's stator active and reactive powers independent control under parameters variation at different rotor operation speeds. The effectiveness of the proposed control scheme is examined in terms of steady-state error, response time, and robustness to parameters variation through experimental studies.

\subsection{DFIG system}

The DFIG system consists of a wound rotor induction generator connected to two back-to-back connected power converters: the grid side converter (GSC) and the rotor side converter (RSC). A typical DFIG system is shown in Figure 1 .

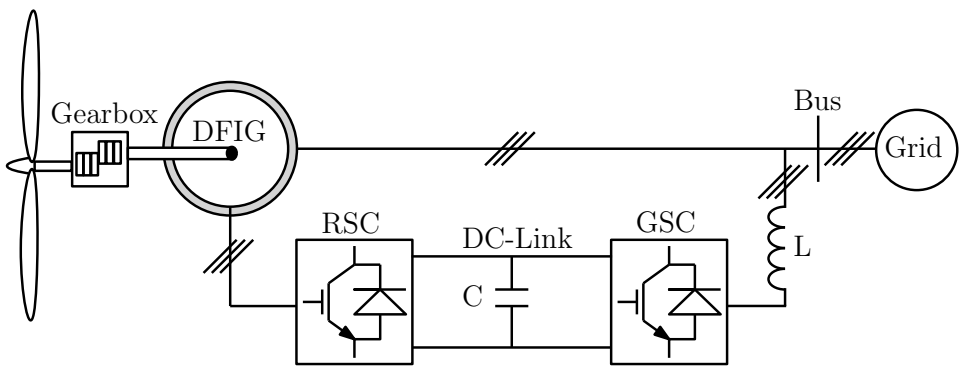

Figure 1: DFIG System

\section{The GSC regulates the DC-link capacitor voltage. The DC-link capacitor is} used as an energy storage element which delivers the required energy between the generator and the grid. Furthermore, the GSC has the ability to absorb or generate reactive power for voltage support requirements. The voltage applied to the DFIG's rotor is generated by the RSC. The main objective of the RSC is to control the rotor currents such that the rotor flux positions are optimally 
oriented with respect to the stator flux such that the required power is developed. Both converters are usually two-level six-switch voltage source converters with IGBT switching elements. Considering the constraint that the peak line voltage is smaller than the DC-link voltage, the six-switch converter can produce a three-phase variable frequency, magnitude, and phase voltage which can alter almost instantaneously considering system limitations, switching frequency for instance [25]. The DFIG electrical equivalent circuit is shown in Figure 2 It is valid for $d q$-axis equations, and the mathematical model is derived from it.

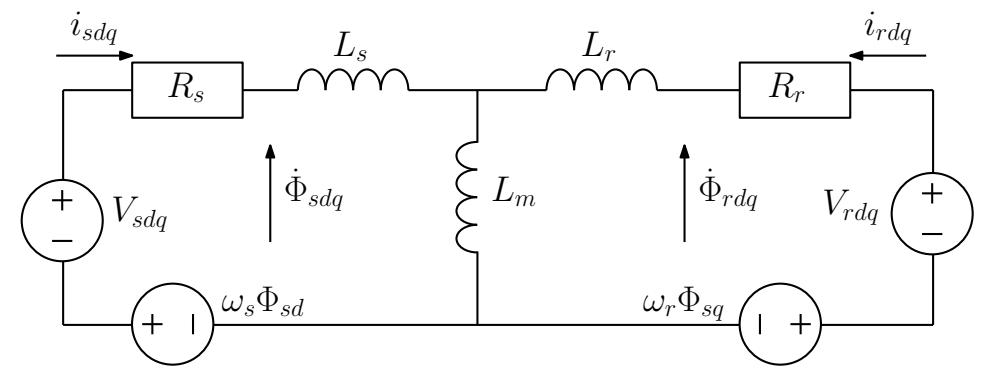

Figure 2: DFIG Equivalent Circuit

Using Kirchhoff voltage law (KVL), the stator and rotor voltages in $d q$-reference frame are given by [26, 27]:

$$
v_{s d q}=R_{s} i_{s d q}+\dot{\Phi}_{s d q} \pm \omega_{s} \Phi_{s d q}
$$

In Equations (1) and (2), the $q$-component voltage is obtained by taking the plus sign in the last term while the $d$-component voltage is obtained by considering the minus sign. The flux of the stator and rotor in the $d q$-reference frame are given by:

$$
\Phi_{s d q}=L_{s} i_{s d q}+L_{m} i_{r d q}
$$


where $\Phi$ is the flux, $i$ is the current, and $v$ is the voltage. Subscripts $s$ and $r$ refer to the stator and rotor while $q$ and $d$ refer to $q$-axis and $d$-axis components. $L$ is the inductance, $R$ is the resistance, $\omega_{s}$ is the system synchronous angular frequency, and $\omega_{r}$ is the rotor angular frequency. The powers are given by:

$$
\begin{aligned}
P_{s} & =-\frac{3}{2}\left(v_{s d} i_{s d}+v_{s q} i_{s q}\right) \\
Q_{s} & =-\frac{3}{2}\left(v_{s q} i_{s d}+v_{s d} i_{s q}\right)
\end{aligned}
$$

If a phase looked loop (PLL) algorithm 28] is used such that $v_{s q}=v_{s}$, and $v_{s d}=0$, Equations (5) and (6) are written as:

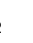

$$
\begin{aligned}
P_{s} & =-\frac{3}{2}\left(v_{s} i_{s q}\right) \\
Q_{s} & =-\frac{3}{2}\left(v_{s} i_{s d}\right)
\end{aligned}
$$

where $v_{s}$ is the stator voltage magnitude. Moreover, in the steady-state regime, the components of the stator flux can be expressed as $\Phi_{s q} \approx 0$ and $\Phi_{s d} \approx \frac{v_{s}}{\omega_{s}}$, which allows the powers to be written as:

$$
\begin{aligned}
P_{s} & =\frac{3}{2} \frac{L_{m} v_{s}}{L_{s}} i_{q r} \\
Q_{s} & =\frac{3}{2} \frac{L_{m} v_{s}}{L_{s}} i_{d r}-\frac{3}{2} \frac{v_{s}^{2}}{\omega_{s} L_{s}}
\end{aligned}
$$

Therefore, the active and reactive powers regulation can be easily realized via the control of the rotor currents. Traditionally, a vector control scheme can be used to regulate the active and reactive power where the controller can be designed by using the dynamic equations of the rotor currents given by [29]:

$$
\begin{aligned}
& { }_{143} \quad \begin{array}{l}
i_{q r} \\
{ }_{144}
\end{array} \quad-\frac{R_{r}}{\sigma L_{r}} i_{q r}-\omega_{s l}\left(\frac{L_{m} v_{s}}{\sigma L_{r} L_{s} \omega_{s}}+i_{d r}\right)+\frac{1}{\sigma L_{r}} v_{q r} \\
& \dot{i}_{d r}=\omega_{s l} i_{q r}-\frac{R_{r}}{\sigma L_{r}} i_{d r}+\frac{1}{\sigma L_{r}} v_{d r}
\end{aligned}
$$


where $\sigma=1-\frac{L_{m}^{2}}{L_{s} L_{r}}$ and $\omega_{s l}=\omega_{s}-\omega_{r}$. However, such a strategy requires either an additional external loop or exact knowledge of the machine parameters to force stator active and reactive powers to be equal to their references. To overcome this drawback, the controller can be designed based on the stator active and reactive powers instead of the rotor currents. Indeed, invoking Equations (9), 10, (11), and 12 and after some mathematical simplifications, the time derivative of the stator power can be expressed as:

$$
\begin{gathered}
\dot{P}_{s}=-\frac{R_{r}}{\sigma L_{r}} P_{s}-\omega_{s l} Q_{s}-\frac{3 \omega_{s l} v_{s}^{2}}{2 \sigma L_{s} \omega_{s}}+\frac{3 L_{m} v_{s}}{2 \sigma L_{s} L_{r}}\left(v_{q r}-\delta_{q}\right) \\
\dot{Q}_{s}=\omega_{s l} P_{s}-\frac{R_{r}}{\sigma L_{r}} Q_{s}-\frac{3 R_{r} v_{s}^{2}}{2 \sigma L_{s} \omega_{s} L_{r}}+\frac{3 L_{m} v_{s}}{2 \sigma L_{s} L_{r}}\left(v_{d r}-\delta_{d}\right)
\end{gathered}
$$

where $\delta_{q}$ and $\delta_{d}$ represent the model uncertainties and external disturbances which are not considered in the DFIG modeling. They include parameters variation and other unknown uncertainties in the system such as the offset resulting from the PWM technique. In order to tackle the need for stator power measurements, an alternative approach consisting of controlling only the stator current is established. In fact, by using Equations (7), (8), (13), and (14), the dynamics of the stator currents are governed by:

$$
\begin{aligned}
& \dot{i}_{s q}=-\frac{R_{r}}{\sigma L_{r}} i_{s q}-\omega_{s l} i_{s d}+\frac{\omega_{s l} v_{s}}{\sigma L_{s} \omega_{s}}-\frac{L_{m}}{\sigma L_{s} L_{r}}\left(v_{q r}-\delta_{q}\right) \\
& \dot{i}_{s d}=\omega_{s l} i_{s q}-\frac{R_{r}}{\sigma L_{r}} i_{s d}+\frac{R_{r} v_{s}}{\sigma L_{s} \omega_{s} L_{r}}-\frac{L_{m}}{\sigma L_{s} L_{r}}\left(v_{d r}-\delta_{d}\right)
\end{aligned}
$$

Finally, Equations (15) and (16) are written as:

$$
\dot{i}_{s q}=-a i_{s q}+F_{q}+b\left(v_{q r}-\delta_{q}\right)
$$

$$
\dot{i}_{s d}=-a i_{s d}+F_{d}+b\left(v_{d r}-\delta_{d}\right)
$$

where $a=\frac{R_{r}}{\sigma L_{r}}, F_{q}=-\omega_{s l} i_{s d}+\frac{\omega_{s l} v_{s}}{\sigma L_{s} \omega_{s}}, b=-\frac{L_{m}}{\sigma L_{s} L_{r}}$, and $F_{d}=\omega_{s l} i_{s q}+$ $\frac{R_{r} v_{s}}{\sigma L_{s} \omega_{s} L_{r}}$. Under an exact knowledge of $v_{s}$ the stator active and reactive powers can be independently controlled by regulating the stator current components. 


\section{Proposed control method}

The proposed control strategy consists of a state-feedback control law and a disturbance observer to compensate for the effect caused by the matched disturbances $\delta_{q}$ and $\delta_{d}$. The composite controller is derived based on the dynamic equations of stator currents defined by Equations (15) and 16).

\subsection{State-feedback controller design}

The control objective is to force the stator currents to track their references within a specified rise time and a zero steady-state error. Such an objective can be achieved by designing a state-feedback control law [30, 31, so that the closed-loop error dynamics are governed by:

$$
\dot{e}_{q}=-K_{q} e_{q} ; \quad \dot{e}_{d}=-K_{d} e_{d}
$$

where $e_{q}=i_{s q r e f}-i_{s q}$ and $e_{d}=i_{s d r e f}-i_{s d}$ are the tracking errors, and $i_{\text {sqref }}$ and $i_{\text {sdref }}$ are the $q$-axis and the $d$-axis stator current references respectively. The controller gains $K_{q}$ and $K_{d}$ must be selected to be positive to guarantee the stability of the closed-loop system. More specifically, the gain $K_{q}$ and $K_{d}$ can be selected based on the desired performance specification in terms of rise time. Combining Equations (17), (18), and (19), the controller can be expressed as:

$$
\begin{aligned}
& v_{q r}=\frac{1}{b}\left(K_{q} e_{q}+\dot{i}_{\text {sqref }}+a i_{s q}-F_{q}+b \delta_{q}\right) \\
& v_{d r}=\frac{1}{b}\left(K_{d} e_{d}+\dot{i}_{s d r e f}+a i_{s d}-F_{d}+b \delta_{d}\right)
\end{aligned}
$$

It is clear that the information about the uncertainties $\delta_{q}$ and $\delta_{d}$ is required to practically implement the state-feedback control law described by the above equations. Such a requirement reveals the need for a disturbance estimator as it is not possible to measure the unknown disturbance. Thus, the disturbances $\delta_{q}$ and $\delta_{d}$ are replaced in the control law by their estimates $\hat{\delta}_{q}$ and $\hat{\delta}_{d}$ for real-time implementation. 


\subsection{Disturbance observer design}

The disturbance observer main purpose is to estimate the unknown disturbances $\delta_{q}$ and $\delta_{d}$. Invoking $(20)-21$, the disturbance observer can be designed as [32, 33]:

$$
\begin{aligned}
& \dot{\hat{\delta}}_{q}=l_{q}\left(\delta_{q}-\hat{\delta}_{q}\right)=l_{q}\left(\frac{1}{b}\left(-\dot{i}_{s q}-a i_{s q}+F_{q}+b v_{q r}\right)-\hat{\delta}_{q}\right) \\
& \dot{\hat{\delta}}_{d}=l_{d}\left(\delta_{d}-\hat{\delta}_{d}\right)=l_{d}\left(\frac{1}{b}\left(-\dot{i}_{s d}-a i_{s d}+F_{d}+b v_{d r}\right)-\hat{\delta}_{d}\right)
\end{aligned}
$$

where $l_{q}$ and $l_{d}$ are the observer gains. By assuming that the disturbance varies slowly and has a constant steady-state value, i.e. $\dot{\delta}_{q d}=0$, the disturbance estimation error dynamics is governed by $\left(\dot{\hat{\delta}}_{d q}-\dot{\delta}_{q d}\right)=-l_{q d}\left(\hat{\delta}_{q d}-\delta_{d q}\right)$ which implies that $l_{q}$ and $l_{d}$ must be chosen to be positive to guarantee the asymptotic stability of the disturbance observer. More specifically, it can be concluded that the convergence rate of the disturbance observer depends on the observer gains. The main drawback of the disturbance observer is that the time derivative of the stator current is required to estimate the disturbance which is not an easy task because of the measurement noises. To overcome this issue, new variables $z_{q}$ and $z_{d}$ are introduced to implement the observer without involving the unmeasurable variables $\dot{i}_{s q}$ and $\dot{i}_{s d}$. Thus, the lumped disturbances can be estimated as:

$$
\dot{z}_{q}=-l_{q} z_{q}+\frac{l_{q}}{b}\left(l_{q}-a\right) i_{s q}+\frac{l_{q}}{b} F_{q}+l_{q} v_{q r}
$$

where $\hat{\delta}_{q}=z_{q}-\frac{l_{q}}{b} i_{s q}$ and $\hat{\delta}_{d}=z_{d}-\frac{l_{d}}{b} i_{s d}$. In this system, $\dot{i}_{s q}$ and $\dot{i}_{s d}$ have the same dynamics; therefore, $l_{q}$ and $l_{d}$ are considered to be equal. The proposed control strategy diagram is shown in Figure 3.

\section{Results and discussions}

This section is divided into four subsections. The first subsection briefly describes the DFIG experimental setup that is used to validated the proposed 


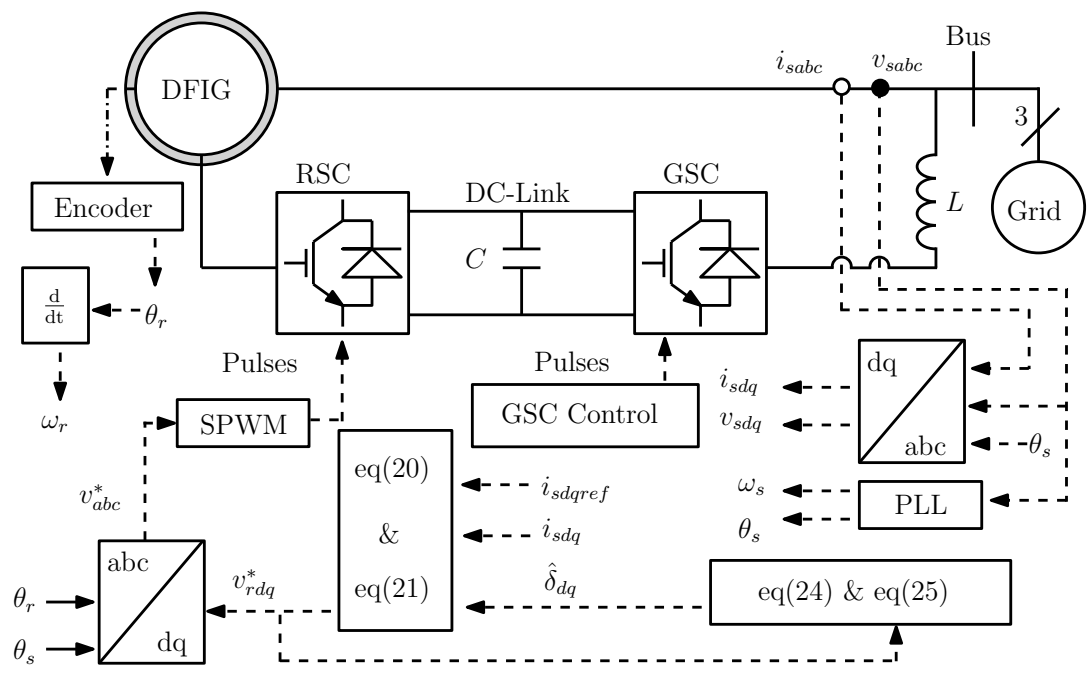

Figure 3: Proposed control strategy diagram

control method. The second subsection describes the way of selecting the proposed control method gains. The third subsection investigates the proposed control performance under speed variations. This includes the DFIG operation under variable wind speeds. The last subsection examines the robustness of the proposed control method under parameters uncertainties.

\subsection{DFIG experimental setup}

The experimental setup that is used to validate the proposed control method is shown in Figure 4. It consists of a $2 \mathrm{~kW}$ DFIG coupled to a controlled induction motor which acts like a wind emulator. The rotor position and speed are measured by an incremental encoder mounted on the DFIG. Both GSC and RSC are controlled by the digital signal processing (DSP) board dSPACE DS1103, which is equipped with Power PC 750GX (Master processor) running at $1 \mathrm{GHz}$, and a Texas Instruments TMS320F240 DSP (slave processor) running at $20 \mathrm{MHz}$. Also, both converters are Danfoss AutomationDrive FC302 controlled by interface and protection card. The controller sampling time is $125 \mu \mathrm{s}$ and the PWM switching frequency is $8000 \mathrm{~Hz}$ for both GSC and RSC. The system parameters are summarized in Table 1 . 


\subsection{Proposed control method gains selection}

In the absence of uncertainties (nominal system), the closed-loop system under the proposed controller can be expressed as a first order system whose time constant is equal to $\frac{1}{K}$. Therefore, under a step input, the closed-loop settling time $T_{s t}$ is given by:

$$
K \approx \frac{4}{T_{s t}}
$$

For example, if a rise time equals $4 \mathrm{~ms}$ is desired, the controller gain should be 1000. In the experiment, the gain should be chosen to be as large as feasible to have a fast response. From a practical standpoint, the control gain $K$ is limited for several reasons such as machine ratings, converters ratings, and limitation of the control effort. The observer gain is similarly chosen; higher the value of the observer gain, faster the disturbance estimation. However, measurement noises put a practical limit on how large the observer gain could be. In other words, large observer gain may magnify the measurement noises. In this paper, the controller gains $K_{q}$ and $K_{d}$ are chosen to be equal to 1500 while the observer gains $l_{q}$ and $l_{d}$ are selected to be equal to 10 .

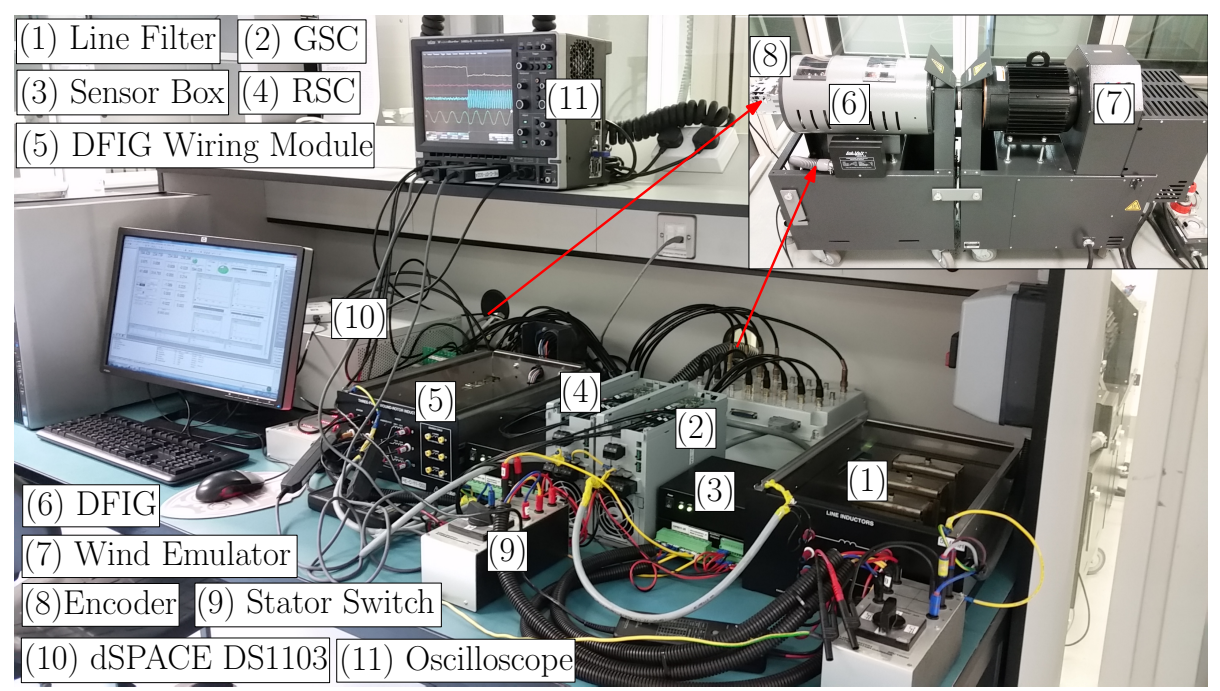

Figure 4: DFIG experimental setup 


\subsection{Speed variation tests}

An experiment that mimics realistic operation and considers variation of wind speed is presented in this subsection. In this experiment, a random wind speed profile is implemented. The wind turbine model 34 is used to relate the wind speed with rotor speed, and maximum power point tracking method (MPPT) [35] is applied. Figure 5 shows the proposed controller response. It is clear that the actual power follows its reference under wind speed fluctuations.

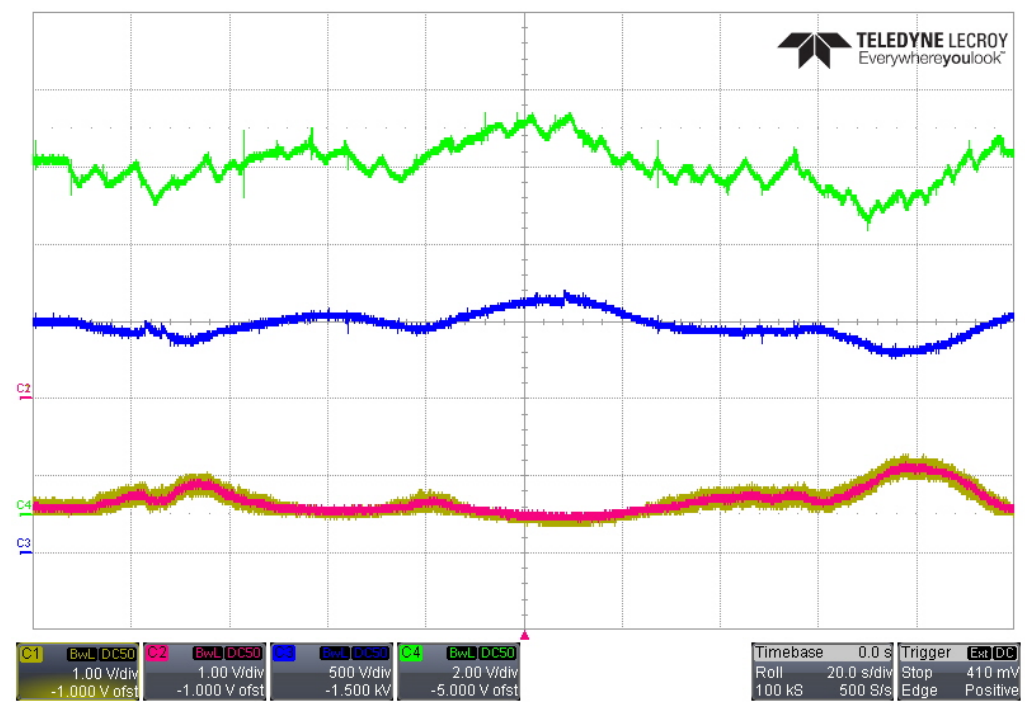

Figure 5: Random fluctuating wind speed with mppt: channel one (yellow) stator q-axis current $(1 \mathrm{~V}=1 \mathrm{~A})$, channel two (red) the reference stator $q$-axis current $(1 \mathrm{~V}=1 \mathrm{~A})$, channel three (blue) rotor speed $(1 \mathrm{~V}=1 \mathrm{RPM})$, channel four (green) wind speed $(1 \mathrm{~V}=1 \mathrm{~m} / \mathrm{s})$

Another experiment where the reference power is kept constant is shown in Figure. 6. It can be inferred from Figure. 6 that the controller is able to control the DFIG stator power to the desired reference power despite the speed variation. The DFIG rotor speed does not change sharply due to the turbine model consideration as wind turbine inertia and equation of motion are considered. Here, it is important to emphasize that the wind turbine emulator (induction motor and drive) has limited dynamics. This explains why it is not possible to sharply change the DFIG rotor speed. 


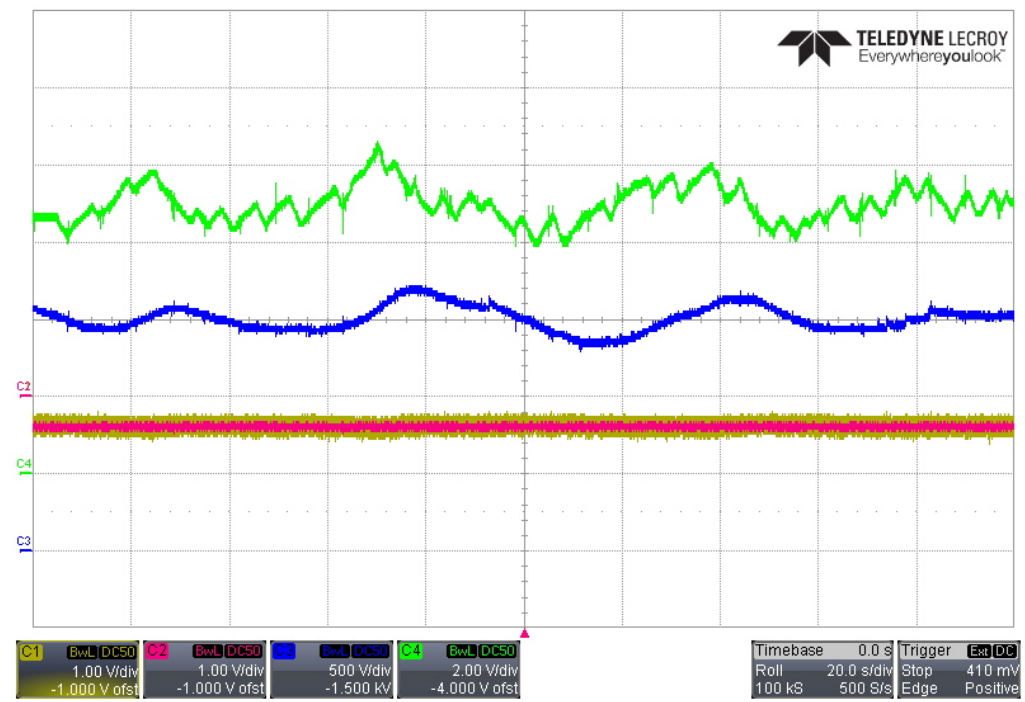

Figure 6: Random fluctuating wind speed without mppt: channel one (yellow) stator q-axis current $(1 \mathrm{~V}=1 \mathrm{~A})$, channel two (red) the reference stator $q$-axis current $(1 \mathrm{~V}=1 \mathrm{~A})$, channel three (blue) rotor speed $(1 \mathrm{~V}=1 \mathrm{RPM})$, channel four (green) wind speed $(1 \mathrm{~V}=1 \mathrm{~m} / \mathrm{s})$

Figure 7 shows the system instantaneous response to a step change in the stator active power from $0 \mathrm{~W}$ to $1000 \mathrm{~W}$ while the reactive power reference is set to 0 Var at sub-synchronous speed $(1300 \mathrm{rpm})$. It can be clearly seen from Figure 7 that the active power follows its reference and zero steady-state error is obtained. Also, the independent behavior of the stator active and reactive powers is ensured since the step change in the stator active power did not affect the stator reactive power. This can also be inferred from Figure 8 where a step change in the stator reactive power from 0 VAR to -500 Var is made while the stator active power reference is kept $0 \mathrm{~W}$. The same step change in the stator active power is performed under synchronous speed (1500 rpm) as shown in Figure 9 and at super-synchronous speed (1700 rpm) as shown in Figure 10 The three tests show that the proposed control method has good transient and steady-state performances. 


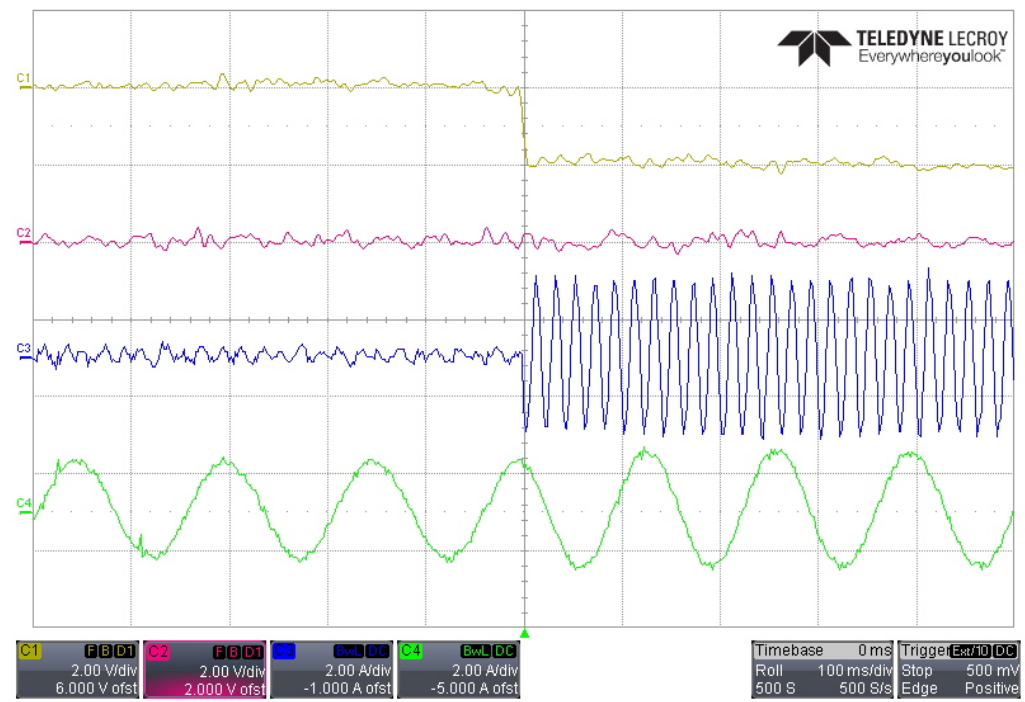

Figure 7: Step change in active power at sub-synchronous speed $1300 \mathrm{rpm}$ : channel one (yellow) stator $q$-axis current, channel two (red) stator $d$-axis current, channel three (blue) stator current phase- $a$, channel four (green) rotor current phase- $a$

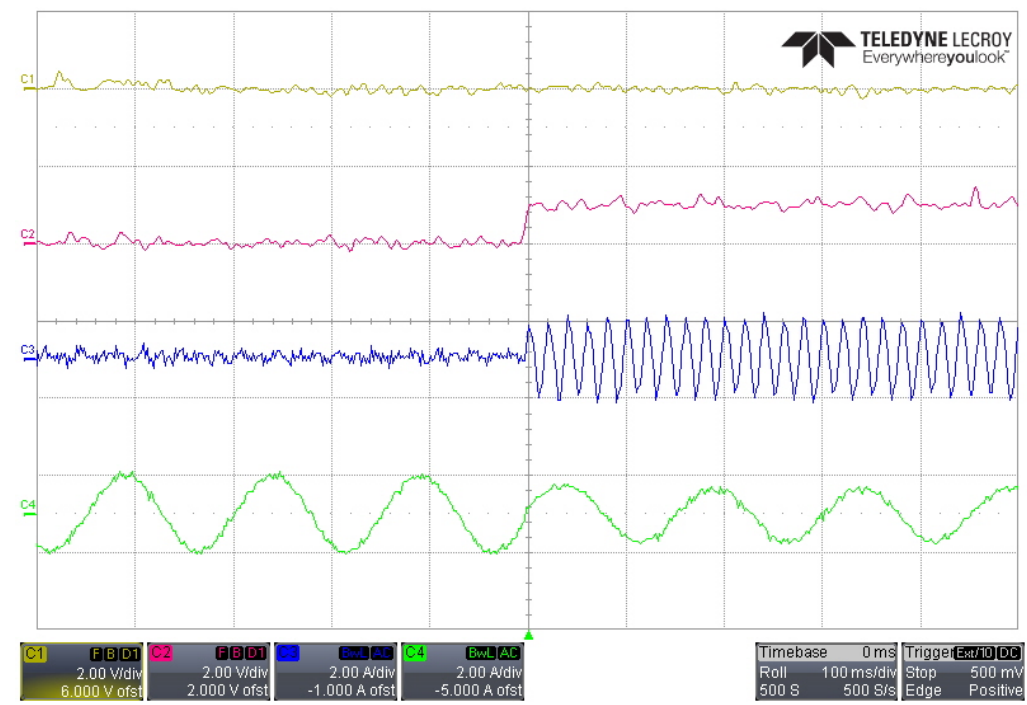

Figure 8: Step change in reactive power at sub-synchronous speed $1300 \mathrm{rpm}$ : channel one (yellow) stator $q$-axis current, channel two (red) stator $d$-axis current, channel three (blue) stator current phase- $a$, channel four (green) rotor current phase- $a$ 


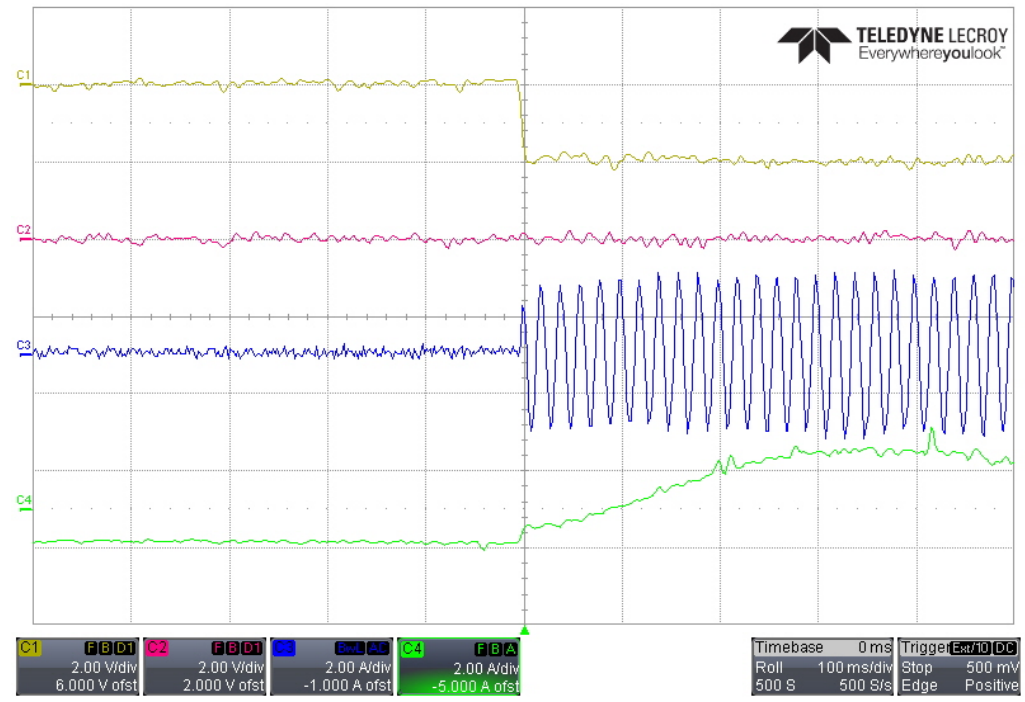

Figure 9: Step change in active power at synchronous speed $1500 \mathrm{rpm}$ : channel one (yellow) stator $q$-axis current, channel two (red) stator $d$-axis current, channel three (blue) stator current phase- $a$, channel four (green) rotor current phase- $a$

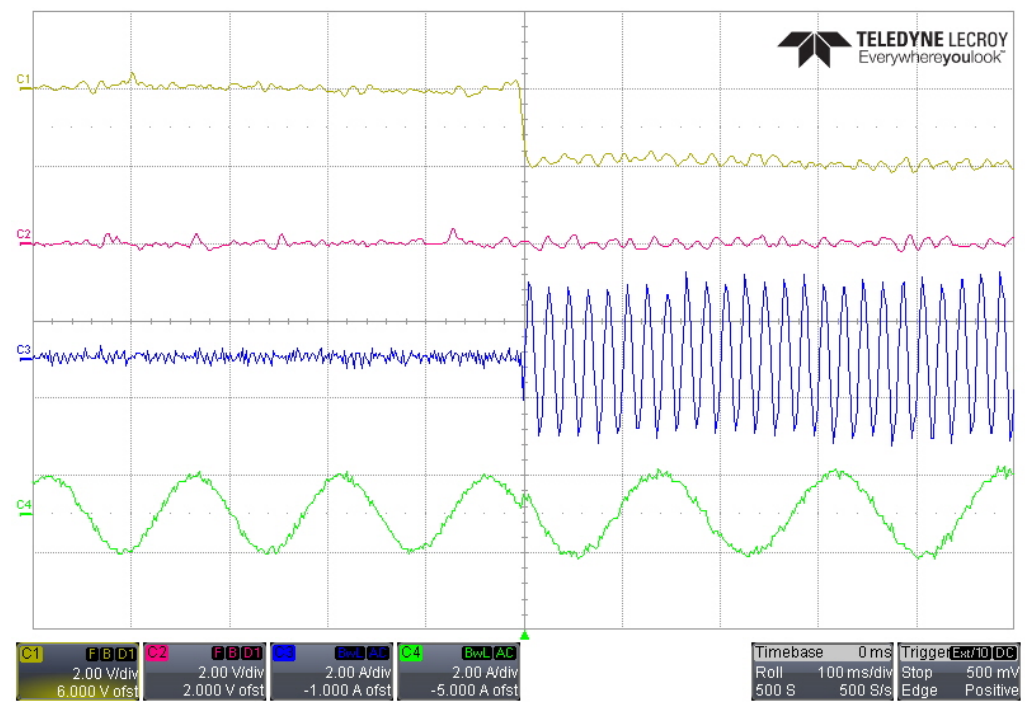

Figure 10: Step change in active power at super-synchronous speed $1700 \mathrm{rpm}$ : channel one (yellow) stator $q$-axis current, channel two (red) stator $d$-axis current, channel three (blue) stator current phase- $a$, channel four (green) rotor current phase- $a$ 


\subsection{Robustness tests}

Figure 11 shows a robustness test where the disturbance observer is disabled during power control operation. The DFIG stator reference active power is set to $500 \mathrm{~W}$ or $\left(i_{q s} \approx-1 A\right)$ and reactive power to 0Var. Initially, both controller and observer are enabled and both active and reactive powers are well controlled to desired references. At $t \approx-3 s$, the disturbance observer is disabled $(t=0 s$ is in the middle). After disabling the disturbance observer, a clear steady state error is reviled. The reason is that the real DFIG system parameters do not exactly match the controller parameters, and the state-feedback controller alone cannot compensate for this mismatch. At $t \approx 2 s$, the disturbance observer is enabled again and the steady state error is eliminated. The disturbance observer requires some time to estimate the uncertainty. This time depends on the controller and observer gains. In real hardware experiment, it is difficult to physically change the system parameters. Therefore, the system parameters are set incorrectly in the controller to mimic a change in the machines parameters.

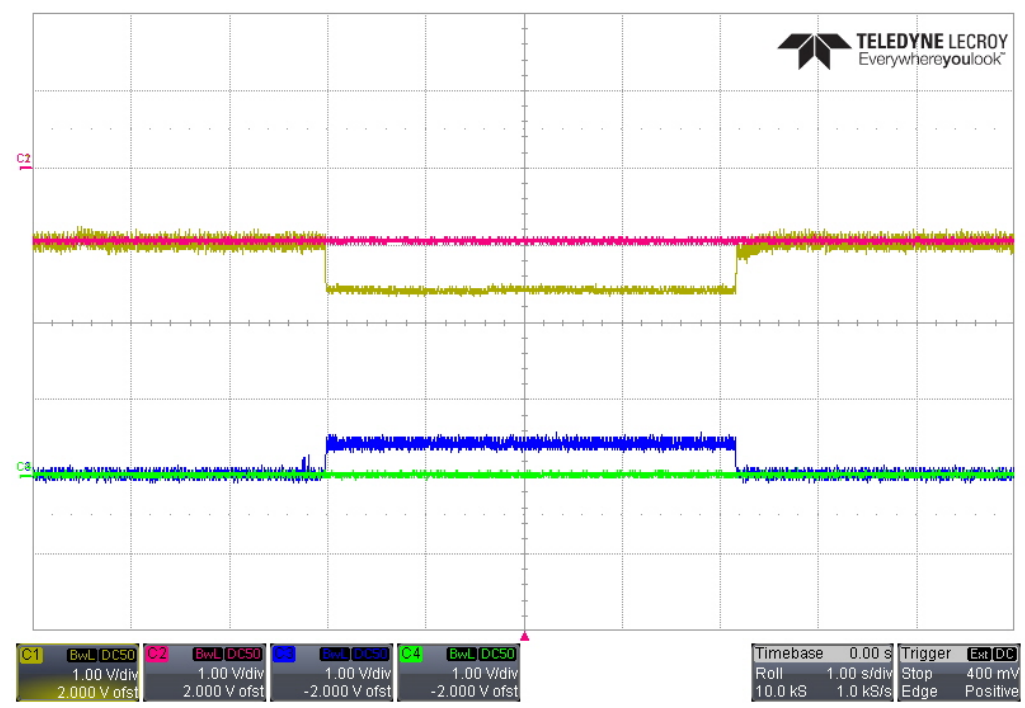

Figure 11: Disable DO: channel one (yellow) stator $q$-axis current $(1 \mathrm{~V}=1 \mathrm{~A})$, channel two (red) the reference stator $q$-axis current $(1 \mathrm{~V}=1 \mathrm{~A})$, channel three (blue) stator $d$-axis current $(1 \mathrm{~V}=1 \mathrm{~A})$, channel four (green) the reference stator $d$-axis current $(1 \mathrm{~V}=1 \mathrm{~A})$ 
Figure 12 shows another robustness test were a system parameter is changed. The system parameter $b$ is reduced by $20 \%$ at $t \approx-8 s$, returned to nominal value $0 \%$ at $t \approx-4$, and increased by $30 \%$ at $t \approx 3 s(t=0 s$ is in the middle). These parameter variations ranges are very high since real parameters cannot change by this level in reality, but they are performed to test the proposed controller robustness. It is clear that the disturbance observer is able to estimate the lumped disturbances, as the steady-state error is well removed, and the power is well regulated to the desired reference value. Figure 13 shows a zoomed response to reduction in parameter $b$ by $20 \%$. The change in parameter $b$ was applied because change in this parameter is clear. Changes in parameter $a$ have minimal effect and cannot be clearly seen. In addition, parameters $F_{q}$ and $F_{d}$ are based on the measurements, and it is assume that access to all states is available. However, the proposed control method behavior is expected to be similar under uncertainties in $F_{q}$ and $F_{d}$.

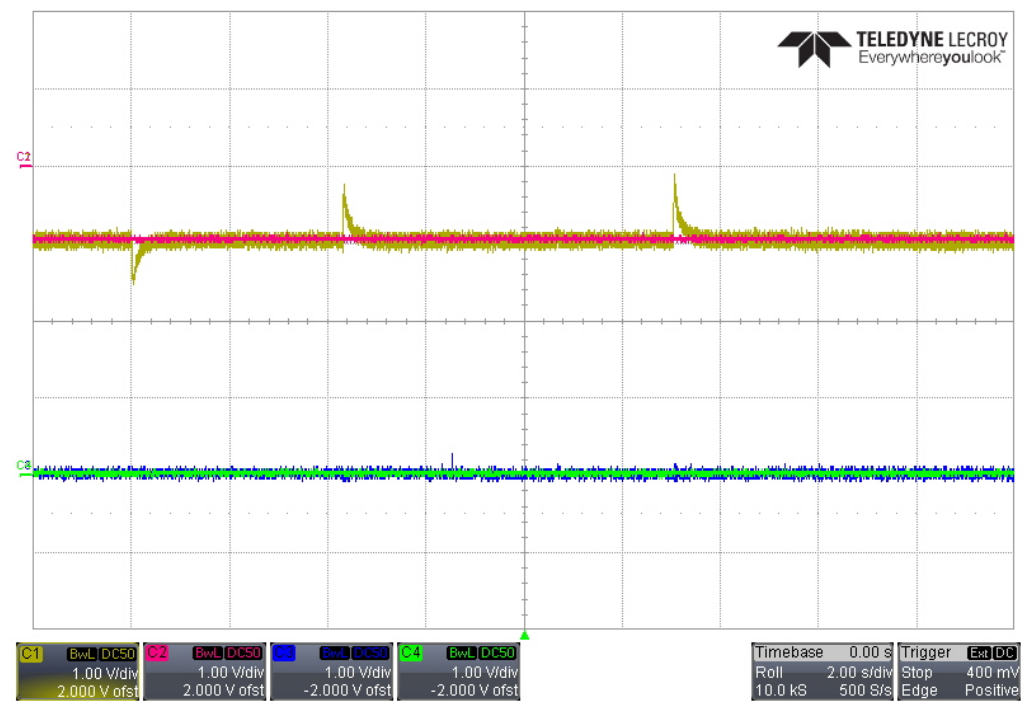

Figure 12: System response under parameters uncertainty: channel one (yellow) stator $q$-axis current $(1 \mathrm{~V}=1 \mathrm{~A})$, channel two (red) the reference stator $q$-axis current $(1 \mathrm{~V}=1 \mathrm{~A})$, channel three (blue) stator $d$-axis current $(1 \mathrm{~V}=1 \mathrm{~A})$, channel four (green) the reference stator $d$-axis current $(1 \mathrm{~V}=1 \mathrm{~A})$ 


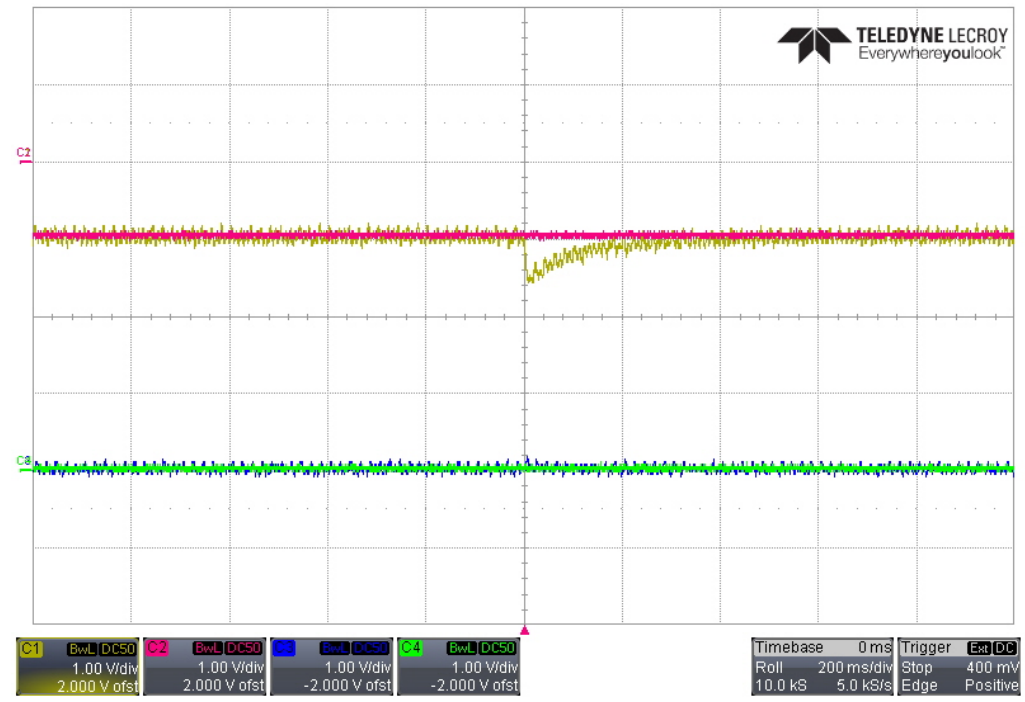

Figure 13: Zoomed System response under parameters uncertainty: channel one (yellow) stator $q$-axis current $(1 \mathrm{~V}=1 \mathrm{~A})$, channel two (red) the reference stator $q$-axis current $(1 \mathrm{~V}=1 \mathrm{~A})$, channel three (blue) stator $d$-axis current $(1 \mathrm{~V}=1 \mathrm{~A})$, channel four (green) the reference stator $d$-axis current $(1 \mathrm{~V}=1 \mathrm{~A})$

\section{Conclusion}

A robust control strategy for doubly fed induction generator's (DFIG) rotor side converter (RSC) is presented in this paper as an attempt to control the generated stator real and reactive powers. It consists of a combination of a state-feedback control law and a disturbance observer where the controller ensures the transient performance while the observers ensures zero steady-state error. More specifically, an accurate control of the active and reactive powers can be obtained with the proposed control strategy without the need for a precise knowledge of the DFIG parameters. To the best of our knowledge, the proposed composite controller has not been practically applied to DFIG based wind energy conversion system. Experimental tests are conducted to verify the effectiveness of the composite controller in terms of transient response and parameter uncertainties under different operating conditions. The results show the feasibility of the proposed controller and its simple design and implementation. 


\section{Acknowledgment}

This work was supported by the project LTR14004 of ADNOC Research and Innovation Center (ADRIC).

\section{Appendix}

The DFIG system parameters are summarized in Table 1.

Table 1: DFIG system parameters

\begin{tabular}{|l|l|l|}
\hline Parameter & Symbol & Value \\
\hline Rated power & $P_{r}$ & $2 \mathrm{~kW}$ \\
Nominal voltage & $V_{s}$ & $415 \mathrm{~V}$ (L-to-L) \\
Turn ratio & $m$ & $1 / 3$ \\
Stator resistance & $R_{s}$ & $2.26 \Omega$ \\
Rotor Resistance & $R_{r}$ & $1.767 \Omega$ \\
Stator inductance & $L_{s}$ & $20 \mathrm{mH}$ \\
Rotor inductance & $L_{r}$ & $20 \mathrm{mH}$ \\
Mutual inductance & $L_{m}$ & $325.3 \mathrm{mH}$ \\
Number of poles & $P$ & $2($ pair poles $)$ \\
System frequency & $f$ & $50 \mathrm{~Hz}$ \\
\hline
\end{tabular}

\section{References}

[1] G. W. E. Council, Global wind report: Annual market update, Global Wind Energy Council.

[2] M. Tazil, V. Kumar, R. C. Bansal, S. Kong, Z. Y. Dong, W. Freitas, H. D. Mathur, Three-phase doubly fed induction generators: an overview, IET Electric Power Appl. 4 (2) (2010) 75-89. doi:10.1049/iet-epa.2009. 0071 .

[3] B. Wu, Y. Lang, N. Zargari, S. Kouro, Power conversion and control of wind energy systems, John Wiley \& Sons, 2011. 
[4] J. Mohammadi, S. Vaez-Zadeh, S. Afsharnia, E. Daryabeigi, A combined vector and direct power control for DFIG-based wind turbines, IEEE Trans. Sustainable Enery 5 (3) (2014) 767-775. doi:10.1109/TSTE. 2014. 2301675

[5] G. D. Marques, M. F. Iacchetti, A self-sensing stator-current-based control system of a DFIG connected to a dc-link, IEEE Trans. Ind. Electron. 62 (10) (2015) 6140-6150. doi:10.1109/TIE.2015.2426675

[6] M. K. Bourdoulis, A. T. Alexandridis, Direct power control of DFIG wind systems based on nonlinear modeling and analysis, IEEE J. Emerging Sel. Topics Power Electron. 2 (4) (2014) 764-775. doi:10.1109/JESTPE. 2014. 2345092 .

[7] S. Li, T. A. Haskew, K. A. Williams, R. P. Swatloski, Control of DFIG wind turbine with direct-current vector control configuration, IEEE Trans. Sustainable Enery 3 (1) (2012) 1-11. doi:10.1109/TSTE.2011.2167001.

[8] J. P. da Costa, H. Pinheiro, T. Degner, G. Arnold, Robust controller for DFIGs of grid-connected wind turbines, IEEE Trans. Ind. Electron. 58 (9) (2011) 4023-4038. doi:10.1109/TIE.2010.2098630

[9] A. Susperregui, J. Jugo, I. Lizarraga, G. Tapia, Automated control of doubly fed induction generator integrating sensorless parameter estimation and grid synchronisation, IET Renew. Power Gener. 8 (1) (2014) 76-89. doi:10.1049/iet-rpg.2013.0045.

[10] R. K. Patnaik, P. K. Dash, Fast adaptive back-stepping terminal sliding mode power control for both the rotor-side as well as grid-side converter of the doubly fed induction generator-based wind farms, IET Renew. Power Gener. 10 (5) (2016) 598-610. doi:10.1049/iet-rpg.2015.0286.

[11] J. Hu, H. Nian, B. Hu, Y. He, Z. Q. Zhu, Direct active and reactive power regulation of DFIG using sliding-mode control approach, IEEE 
Trans. Energy Convers. 25 (4) (2010) 1028-1039. doi:10.1109/TEC.2010. 2048754

[12] X. Liu, X. Kong, Nonlinear model predictive control for DFIG-based wind power generation, IEEE Trans. Autom. Sci. Eng. 11 (4) (2014) 1046-1055. doi:10.1109/TASE.2013.2284066.

[13] S. Bayhan, H. Abu-Rub, O. Ellabban, Sensorless model predictive control scheme of wind-driven doubly fed induction generator in dc microgrid, IET Renew. Power Gener. 10 (4) (2016) 514-521. doi:10.1049/iet-rpg. 2015. 0347 .

[14] R. Errouissi, A. Al-Durra, S. M. Muyeen, S. Leng, F. Blaabjerg, Offset-free direct power control of dfig under continuous-time model predictive control, IEEE Trans. Power Electron. 32 (3) (2017) 2265-2277. doi:10.1109/TPEL. 2016.2557964

[15] Y. Zhang, J. Hu, J. Zhu, Three-vectors-based predictive direct power control of the doubly fed induction generator for wind energy applications, 1. IEEE Trans. Power Electron. 29 (7) (2014) 3485-3500. doi:10.1109/TPEL. 2013.2282405

[16] L. Xu, D. Zhi, B. W. Williams, Predictive current control of doubly fed induction generators, IEEE Trans. Ind. Electron. 56 (10) (2009) 4143-4153. doi:10.1109/TIE.2009.2017552.

[17] E. Golubovic, E. E. Özsoy, M. Gökaşan, A. Sabanovic, Design and analysis of robust rotor current controller for doubly fed induction generator, in: 39th Annual Conf. of the IEEE Industrial Electronics Society, IECON 2013, 2013, pp. 5260-5265. doi:10.1109/IECON.2013.6699990.

[18] M. Derafshian, N. Amjady, Optimal design of power system stabilizer for power systems including doubly fed induction generator wind turbines, Energy 84 (2015) 1-14. 
[19] A. Ghaffari, M. Krstić, S. Seshagiri, Power optimization and control in wind energy conversion systems using extremum seeking, IEEE Trans. Control Syst. Technol. 22 (5) (2014) 1684-1695. doi:10.1109/TCST. 2014. 2303112

[20] S. Bayhan, S. Demirbas, H. Abu-Rub, Fuzzy-PI-based sensorless frequency and voltage controller for doubly fed induction generator connected to a DC microgrid, IET Renew. Power Gener. 10 (8) (2016) 1069-1077. doi: 10.1049/iet-rpg.2015.0504

[21] M. Valikhani, C. Sourkounis, A novel intelligent controller for DFIG-based wind turbine system, in: 2014 IEEE Int. Energy Con. (ENERGYCON), 2014, pp. 44-50. doi:10.1109/ENERGYCON.2014.6850404.

[22] E. B. Muhando, T. Senjyu, A. Uehara, T. Funabashi, Gain-scheduled $\mathrm{H}_{\infty}$ control for WECS via LMI techniques and parametrically dependent feedback part i: Model development fundamentals, IEEE Trans. Ind. Electron. 58 (1) (2011) 48-56. doi:10.1109/TIE.2010.2045317.

[23] G. Rigatos, P. Siano, C. Cecati, A nonlinear H-infinity feedback control approach for asynchronous generators, in: 2015 Int. Con. on Clean Electrical Power (ICCEP), 2015, pp. 460-465. doi:10.1109/ICCEP. 2015. 7177557 .

[24] A. D. Giorgio, A. Mercurio, F. Liberati, Regulation of angular speed and reactive power for a wind turbine applying robust feedback linearization and $\mathrm{H}_{\infty}$ control, in: 2013 21st Mediterranean Con. on Control Automation (MED), 2013, pp. 1316-1321. doi:10.1109/MED.2013.6608890.

[25] C. Sample, Principles of doubly-fed induction generators (DFIG).

[26] G. Abad, J. Lopez, M. Rodriguez, L. Marroyo, G. Iwanski, Doubly fed induction machine: modeling and control for wind energy generation, Vol. 85, John Wiley \& Sons, 2011. 
[27] S. Chondrogiannis, M. Barnes, Stability of doubly-fed induction generator under stator voltage orientated vector control, IET Renew. Power Gener. 2 (3) (2008) 170-180. doi:10.1049/iet-rpg:20070086.

[28] S.-K. Chung, A phase tracking system for three phase utility interface inverters, IEEE Trans. Power Electron. 15 (3) (2000) 431-438. doi: $10.1109 / 63.844502$

[29] A. Tapia, G. Tapia, J. X. Ostolaza, J. R. Saenz, Modeling and control of a wind turbine driven doubly fed induction generator, IEEE Trans. Energy Convers. 18 (2) (2003) 194-204. doi:10.1109/TEC.2003.811727.

[30] H. K. Khalil, J. Grizzle, Nonlinear systems, Vol. 3, Prentice hall New Jersey, 1996.

[31] H. Nian, Y. Song, Direct power control of doubly fed induction generator under distorted grid voltage, IEEE Trans. Power Electron. 29 (2) (2014) 894-905. doi:10.1109/TPEL.2013.2258943.

[32] Y. I. Son, I. H. Kim, D. S. Choi, H. Shim, Robust cascade control of electric motor drives using dual reduced-order PI observer, IEEE Trans. Ind. Electron. 62 (6) (2015) 3672-3682. doi:10.1109/TIE.2014.2374571.

[33] R. Errouissi, S. M. Muyeen, A. Al-Durra, S. Leng, Experimental validation of a robust continuous nonlinear model predictive control based grid-interlinked photovoltaic inverter, IEEE Trans. Ind. Electron. 63 (7) (2016) 4495-4505. doi:10.1109/TIE.2015.2508920.

[34] S. M. Muyeen, J. Tamura, T. Murata, Stability augmentation of a grid-connected wind farm, Springer Science \& Business Media, 2008.

[35] E. Koutroulis, K. Kalaitzakis, Design of a maximum power tracking system for wind-energy-conversion applications, IEEE Trans. Ind. Electron. 53 (2) (2006) 486-494. 